\title{
Evaluation of Electrical and Thermal Conductivity of Polymeric Wastes after Being Doped with Charcoal and Graphite
}

\section{*11ULEANYA KELECHI.OGOCHUKWU}

\author{
Chemistry Programme, School of Science and Technology, National Open University of Nigeria, 14/16 Ahmadu Bello Way, P.M.B. 80067 \\ Victoria Island, Lagos, Nigeria \\ Email:kuleanya@noun.edu.ng, +2348063163725
}

\begin{abstract}
This work being gingered by the big menace being posed on our environment by polymeric waste and it's rechanneling involved the studying of the electrical and thermal conductivities of the polymers PP, PE, PS and nylon66 doped with charcoal and graphite. Five grams of each polymer was mixed with varying concentrations of the dopants (charcoal and graphite). $0 \%, 0.05 \%, 0.10 \%, 0.5 \%, 0.75 \%, 1.00 \%, 1.25 \%$ and $1.5 \%$ concentrations of the dopants were used to mix five grams of each of the polymers. The mixture on melting with heat application was compressed in a wooden mold to form tablets of the doped polymers. On testing for the electrical and thermal conductivities of the doped polymers it was observed that both conductivities were greatly enhanced as the concentrations of the dopants increased. Hence it is evident that those polymeric materials on further modifications can be used for other purposes especially in the industries for example producing capacitors other than being littered and disposed in the environment. (C) JASEM
\end{abstract}

http://dx.doi.org/10.4314/jasem.v20i2.20

KEY WORDS: Polymers, Environment, Pollutant, Dopant, and conductivities

\section{Introduction}

Wastes are in various forms and types, and the existence, management and challenges in human settlements have been of concern to individuals, communities, governments, organizations, research and development ( Rochman CM, Hoh E, Kurobe T, Teh SW (2013), Klika, 2013; Hamer, 2003; Beth, 2012; Evans and Bishop, 2000; Zaini, 2011; Aderogba,2014). It may be elegant to define waste as leftovers, excesses, surpluses, unwanted and remains that are discarded, castoff, rejected, superfluous, dumped and or thrown away. Although one thing is unique to all: they are unwanted materials, at a moment in time, which resulted from processes of production and or transformation of some material resources to another. Though, there are some schools of thought that believe that there is no material entity that is absolutely a waste. In this respect, it means such materials are only awaiting more purposeful uses and or there are not yet technologies of developing them into useful states and or entity (Aderogba, In Press; Chen and Patel, 2012). In other words, wastes are the remnants of productions, processing, nonserviceability, disuse and others that have been discarded and abandoned for wants of immediate use. Many scholars have worked and defined what constitutes wastes in human settlements, and in particular, the challenges posed in human settlements for sustainable development (Beth, 2012; Evans and Bishop, 2000; Weber R, Gaius C, Tysklind M, Johnston P, Forter M, Hollerti H, Heinisch E, Holoubeck I, Lloyd Smith M, Masunaga S, Moccarelli P, Santillo D, Seike N, Symons R, Torres JP, Verta M, Varbelow G, Vijqen J, Watson A, Costner P, Woelz J,
Zenneqq M (2008). There is virtually no where plastics as mold, extrusions, grains and films are not used in reasonable quantities - in laboratories, homes, industries, schools and colleges, tourist centers and etc (Ogwueleke, 2006; Klika, 2013)

Although polymeric wastes forms over $90 \%$ of our daily family wastes in Nigeria, waste management has been a major challenge in the Nigerian society as well as in most African countries owing to the dual problem of increase in waste generation and the poor management of such (Akanmu JO (2000). The challenge however is not peculiar to Nigeria and Africa, (Weber et al., 2008). In Nigeria most refuse dumps constitute majorly of polymers of different forms which include poly ethylene, poly styrene, polypropylene etc. The menace of these wastes can never be over emphasized and thus seeking for more permanent ways of recycling it is the optimal solution.

Most commercially produced organic polymers are electrical insulators. Conductive organic polymers often have extruded delocalized bonds (often composed of aromatic units). When charge carriers (from the addition or removal of electrons) are introduced into the conduction or valence bands, the electrical conductivity increases dramatically. Technically almost all known conductive polymers are semi-conductors due to the band structure and low electronic mobility. However, so called zero band gap conductive polymers may behave like metals. The most notable difference between conductive polymers and inorganic semi-conductors is the mobility, which until very recent was dramatically lower in conductive 
polymers than their inorganic counter parts though recent advancements in molecular self-. assembly are closing that gap(Biodun N. 1997). The world electronic market has shifted its interest and concern to the use and application of conductive polymers in its production developments because of their simplicity and compactness. All hands therefore must be on deck to evolve highly conductive yet cheap polymers from readily available, easily sourced materials in our environment. This work was gingered by the above premise and its concerned was based on how the readily available polymer, polystyrene could be electrically and thermally enhanced by doping with Iron III chloride, graphite and charcoal to help its conductivity such that it can be employed for this essential function since it is evidently clear that already made conductive polymers are not readily available and are of low cost efficiency. Metals are characterized by the presence of free electrons and can conduct electricity; non-metals have few or no electrons and cannot conduct electricity, while semiconductors are in between the two. Plastics are generally known as good electrical insulators (Inzelt G.). Insulators break down for two reasons, firstly, the higher the voltage they must sustain, the greater the strain imposed upon their inter-atomic bonds and hence on their insulating properties. Every insulator has a voltage of a given thickness, beyond which it will break down and conduct either across its surface or throughout the bulk of the material. Secondly, the hotter the insulator, the greater the agitation within its crystal structure and the more likelihood there will be free electrons (Magic K.D, Pelitsky V.E 1984). Conductive polymers are generally not thermoplastics i.e. they are not thermo formable although like insulating polymers they are organic materials. They have an advantage over other polymers because of their process ability which is mainly by dispersion (Naarman H.,2000). The electrical properties of conductive polymers can be fine-tuned using the methods of organic synthesis (Nalwa H.S,2000) and by advanced dispersion techniques (Saricifici N.S,1997). The conductivity of polymers is the result of several processes. In the traditional polymers such as polyethylene, the valence electrons are bound in $\mathrm{sp}^{3}$ hybridized covalent bonds such sigma-bonding electrons have low mobility and do not contribute to the electrical conductivity of the material. Organic insulator decomposes at a temperature of a few hundred degrees centigrade, but ceramic insulators when very hot may conduct quite well. The more firmly restrained the electrons are in a material, the better its insulating properties.

At times, minute amounts of impurities or dopants may be introduced to an insulator to improve conductivity to desired amount and the process is known as doping (Brandup J., Immergent.E.H,1989).These dopants or impurities either introduce mobile or free electrons into the insulator (Parker,P.S 1994). The conductivity of the doped material approaches the conductivity of the best available conductor, that is, silver. At room temperature, the conductivity of polyacetylene approaches the conductivity of copper on a weight basis and exists in cis-configuration at $195^{\circ} \mathrm{K}$ and trans- at room temperature (Nalwa H.S,2000). However in conjugated materials the situation is completely different .Conducting polymers have backbone of contiguous $\mathrm{sp}^{2}$ hybridized carbon centres (Brown L.T, Lemay E. H, Jr., Brusten .E.B, 2009). Conductive polymers are organic polymers that possess electrical, electronic, magnetic, and optical properties of a metal while retaining mechanical properties processibility commonly associated with a conventional polymer (Wanekaya A.K, Lei Y., Bekyarova E., Chen W., Haddon R., 2006). It can also be defined as any system that contains an additive to lower resistivity. The resistivity of unmodified polymers or plastics is $1016 \Omega \mathrm{m}$ while conductive additives can lower resistivity level in steps down to $104 \Omega \mathrm{m}$ resistivity range (Dahman S. J, 1999). This work is focused primarily on the enhancement of their crucial properties: electrical and thermal conductivities that are required of a polymer for it to be accepted for all good uses especially as a semiconductor. Commonly discarded polymers and materials from the environment were used as a means of waste control. Cost management was considered since this has served as a strong limitation for their use. These desired polymers were achieved by doping with dopants to help lower the resistivity of the polymers thus increasing their conductivities. Hence the doping process is the introduction of very small amounts of impurities example $\mathrm{fecl}_{3}$, graphite or charcoal to generate charge carriers since concentrations of dopants causes certain electrons to become unpaired. Doping also lead to the formation of polarons and bipolarons have extended p-orbital system that have more (n-type) or fewer (p-type) valence electrons to increase the conductivity of a semiconductor (Dahman S. J, 1999).

\section{MATERIALS AND METHODS}

All the materials and equipment used for this particular research were sourced from the chemistry and physics research Lab of the Nnamdi Azikiwe University Awka, Cutix Cable Nnewi, Relief Market Onitsha and electronic shops in Onitsha.

White brittle pack used for protecting electronic gadgets which is pure polystyrene, Graphite from dry cell batteries. Electrical weighing balance from mettler Toledo 2007 mode serial no 021-64852350 ENGLAND, Stirring rods, Beakers (PYREX). Electro thermal Heater of about $250^{\circ} \mathrm{c}$ from Barnstaed 2006 model, serial no 10714483 England, Thermometer $360^{\circ} \mathrm{C}$ thermometer, Wooden mould, Karthrometer, 500 mega ohms MASTECH multimeter No. 005-134

$5 \mathrm{~g}$ of the polymer were weighed into a $250 \mathrm{ml}$ beaker and heated at a regulated temperature of $130{ }^{\circ} \mathrm{C}-250$ 
${ }^{\circ} \mathrm{C}$ to melt it using a thermometer and on continuous stirring to maintain a uniform temperature. During the process care was taken not to allow degradation. The dopant of known different percentage concentrations $0.00,0.05,0.10,0.50,0.75,1.00,1.25,1.50$ was added into the beaker containing the polymer and the two mixed thoroughly while heating respectively. The mixture was then poured immediately into the mold and compressed to form doped tablets of polymers. Their electrical conductivities were measured using 500 mega ohms MASTECH multimeter No. 005-1349 .Electrical conductivity is the reciprocal of resitivity, $\mathrm{K}=1 / \mathrm{R}$

Where K -Electrical conductivity, R- Resitivity

The thermal conductivity was measured with ELMER 2AK Kathrometer

Table 1:Formulation of doped polymers

\begin{tabular}{lllll}
\hline \% Dopant & \multicolumn{4}{l}{ Weight of polymers } \\
\cline { 2 - 5 } concerntration & PE & PP & PS & nylon66 \\
$\mathbf{0}$ & 5 & 5 & 5 & 5 \\
$\mathbf{0 . 0 5}$ & 5 & 5 & 5 & 5 \\
$\mathbf{0 . 1}$ & 5 & 5 & 5 & 5 \\
$\mathbf{0 . 5}$ & 5 & 5 & 5 & 5 \\
$\mathbf{0 . 7 5}$ & 5 & 5 & 5 & 5 \\
$\mathbf{1}$ & 5 & 5 & 5 & 5 \\
$\mathbf{1 . 2 5}$ & 5 & 5 & 5 & 5 \\
$\mathbf{1 . 5}$ & 5 & 5 & 5 & 5 \\
\hline
\end{tabular}

Characterization of the Sample (a) The electrical conductivity of the sample was carried out by using 500mega ohms MASTECH multimeter 005-1349. Each sample prepared was tested with the equipment by placing it between the two opposite rods of the multimeter and its resistance taken. Resistivity is the opposition given to flow of current per unit length of material of uniform sectional area and the reciprocal of resistivity was measured as: $\mathrm{K}=\mathrm{I} / \mathrm{R}$ (1) Where $\mathrm{k}=$ Electrical conductivity $\mathrm{R}=$ Resistance

(b) Thermal conductivity was carried out using Elmer $2 \mathrm{AK}$ kathrometer. The results were obtained from the equation below.

$\mathrm{q}=\mathrm{kdt} / \mathrm{dx}(2)$ Where $\mathrm{q}=$ heat flux $(\mathrm{w} / \mathrm{m} 2) \mathrm{dt} / \mathrm{dx}=$ temperature gradient $(\mathrm{k} / \mathrm{m})$

\section{RESULTS AND DISCUSSIONS}

LDPE exists more in the amorphous phase that is the molecules are not arranged in an orderly manner and it possesses a lot of short branches.

PP is in a crystalline form with the molecules better arranged in a straight chain.

PS is amorphous and possesses a dipolar nature. nylon 66 is crystalline and the properties are controlled by the magnitude of the intermolecular forces between the individual chains which come from ----(---CO- NH-)--group. This group is polar and capable of establishing hydrogen bridges.

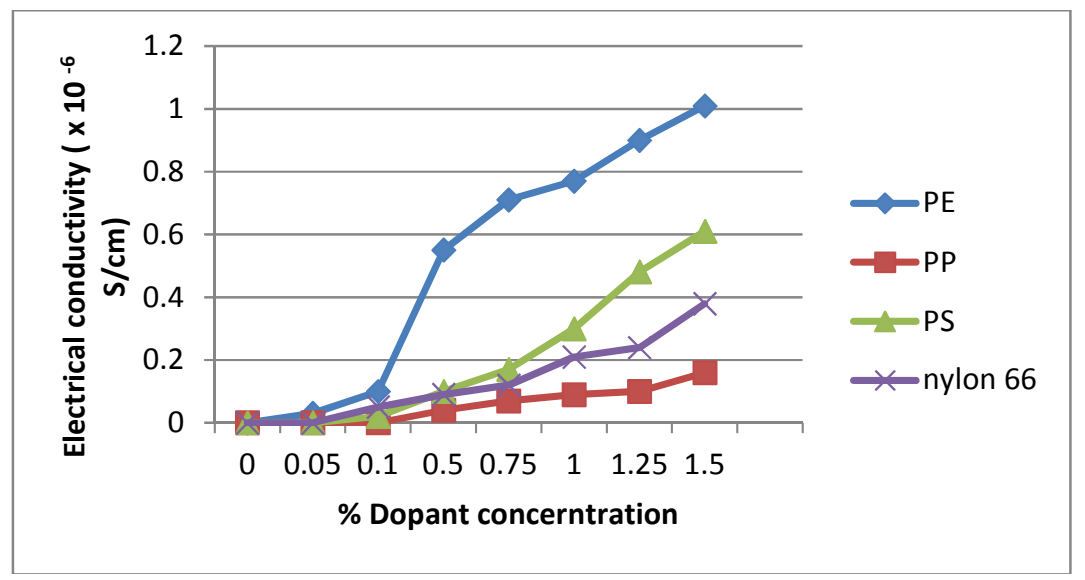

Fig 1: Effects of doping with graphite on the electrical conductivities of the polymers.

Increment in the electrical conductivity of the polymers doped with graphite is probably due to the order of amorphousness; polyethylene being most amorphous in nature with short branches showed the highest increment of the four polymers. It was also found that the electrical conductivity increases with increased dopant concentration in all the four polymers. This could be accounted for by the increasing „"ISLAND OF GRAPHITE ${ }^{\text {ecee }}$ as the concentration of graphite increases. The existence of island was also controlled by disorder in the molecular arrangement of the starting material and homogeneity of the doping process. It was also observed that this increase in the electrical conductivity with increasing dopant concentration was most marked with polyethylene and also followed the same trend as the degree of crystallinity to polystyrene which showed more increment than nylon 66 and polypropylene showed the least increment 


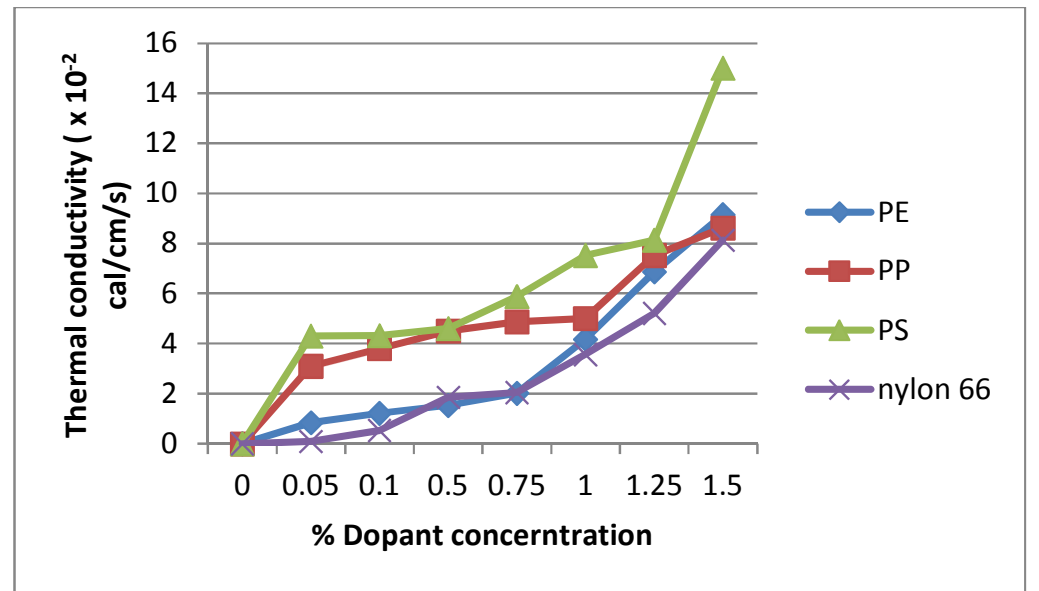

Fig 2: Effects of doping with graphite on the thermal conductivities of the polymers.

In thermal conductivity Polystyrene performed best followed by polypropylene. There was also the spiking that resulted from increased conductivity at lower concentration which disappeared at a concentration of about $0.05 \mathrm{wt}$ percent as evident in polypropylene and $1.25 \mathrm{wt}$ percent in polystyrene, O.75wt percent in nylon 66 and polyethylene. This spike could probably be as a result of increased organization or compactness provided by increased concentration of graphite, which increased heat transfer via photon. The lower concentration spike could be accounted for by electron movements while the higher concentration spike could be accounted for by elastic wave like transfer of heats (photons) through the increased compact structure provided by the graphite and direct transfer of energy from one atom to another. Polyethylene because of its amorphousness also performed poorest but exhibited a spiking from $0.75 \mathrm{wt} \%$ accounted for by the increase in its structural organization through the contribution of hexagonal arrangement of graphite molecules. The behavior of polystyrene which was very outstanding could probably be as a result of di-polarity improvement which made a negligible contribution to the thermal conductivity of its parent form but could be said to have made significant contribution to the thermal conductivity of the doped polystyrene due to its interaction with delocalized electron in the graphite. At higher concentration, the second spike could be from an increased compactness resulting from hexagonal arrangement of the graphite molecules. nylon66; has a crystalline structure whose inter-atomic integrity depends on the polar-CO-NH- side chain. The free electron in graphite could have interacted with the - $\mathrm{CO}-\mathrm{NH}$ - in such a way that the inter atomic forces that determine the compactness of the crystalline structure of nylon 66 was broken therefore disrupting the ease with which energy was transferred from one atom of the polymer to the other thus making nylon 66 a poorer thermal conductor contrary to expectation from its crystalline form.

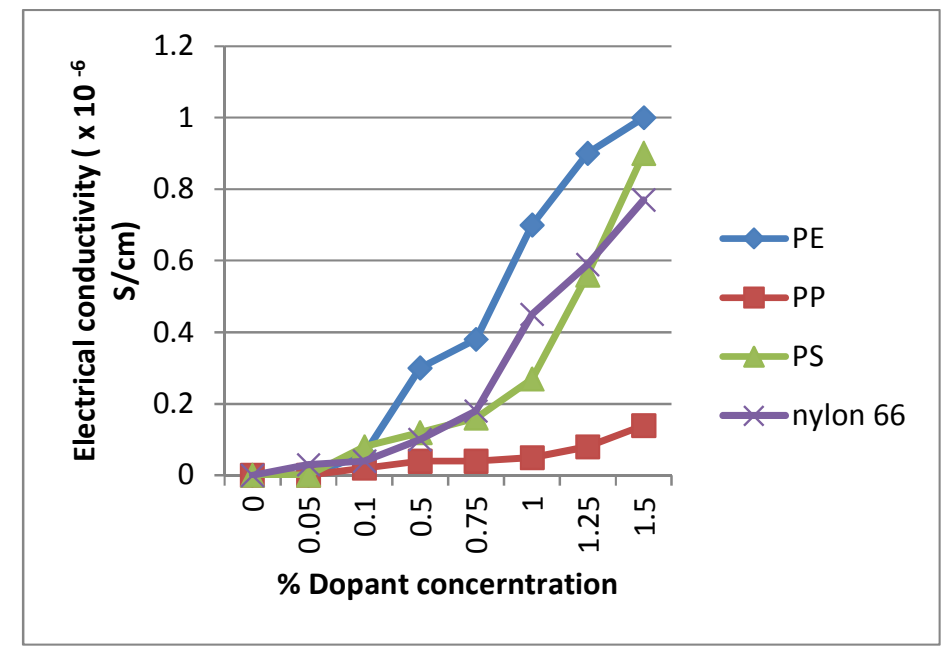

Fig 3: Effects of doping with charcoal on the electrical conductivities of the polymers.

Charcoal is amorphous in nature. Although it has similar layers as found in graphite it conducts electricity better because all the imprisoned electrons in the hexagonal carbon arrangement of the graphite molecules are free (Arene E.O., Kitwood T.M 1976) for movement in the amorphous charcoal. This could 
account for better electrical conductivity in these polymers used because there will be i. More carrier electrons available, more space for hopping in the disordered arrangement of amorphous charcoal. ii. The conductive band of the carbons of the charcoal are brought closer to the valency band of the polymers for movements of electrons and holes. It is important to note the behaviour of nylon66 which improved significantly to compete with PS could be explained by the amphorous charcoal which provides more available electron to add to those of the polar chain and thus significantly improve the electrical conductivity of the nylon 66 to meet the electrical conductivity of polystyrene (PS) which its behaviour is accounted for by the amorphous nature of the constituent hydrocarbon.

The most crystalline polymer PP also exhibited the least electrical conductivity. There was also increased electrical conductivity with increasing concentration of dopants. This could also be explained by the increasing Island of charcoal in the polymer as the concentration of dopants increases. (Seymour R.B, Chery.T. 1986) This behaviour is more marked with amorphousness of the polymers thus this could explain why PS at higher concentration started to exhibit a better activity than nylon 66 that sort of competing with it at the lower concentrations.

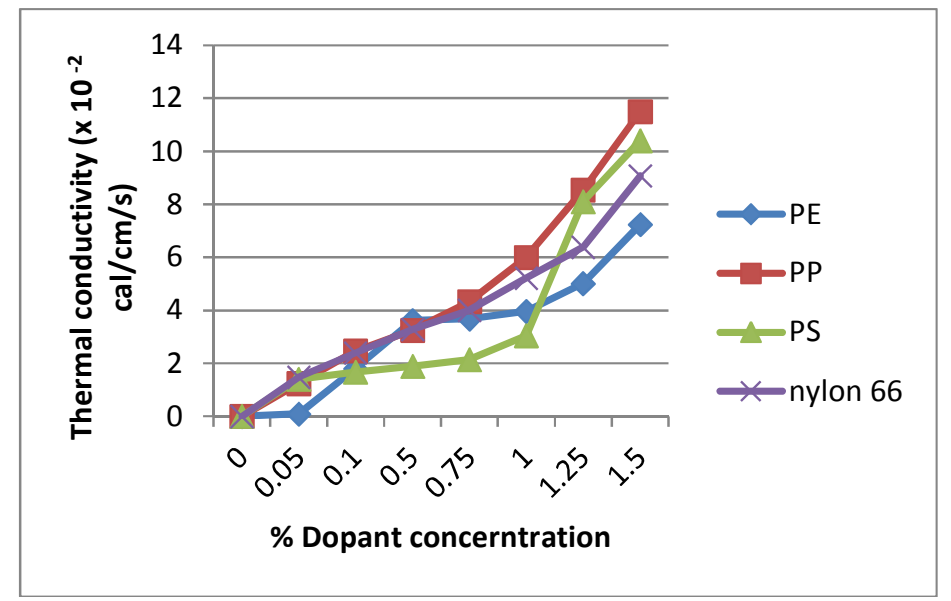

Fig 4: Effects of doping with charcoal on the thermal conductivities of the polymers.

PS performed best followed by PP in thermal conductivity. There was spiking that results from increased thermal conductivity at lower concentration. This which could be attributed to the increased organization or compactness provided by increased concentration of charcoal, which now increases heat transfer via phonon. It can be explained that the lower concentration spike is accounted for by electron movements while the higher concentration spike is accounted for by elastic wave like transfer of heats(photons) through the increased compact structure provided by the charcoal and direct transfer of energy from one atom to another.

The results show that the addition of the dopants increased the electrical and thermal conductivities of the polymers although the rate of enhancement is dependent on the intrinsic properties of the individual polymers. The most notable difference between conductive polymers and inorganic semiconductors is the mobility, which until very recently was dramatically lower in conductive polymers than their inorganic counterparts, though recent advancements in molecular self-assembly are closing that gap which involves doping them. Typically "doping" the polymers involves actually oxidizing/reducing of the compound. When charge carriers (from the addition or removal of electrons) are introduced into the conduction or valence bands the electrical conductivity increases dramatically. This low charge carrier mobility is related to amorphous and disordered nature of the solid state nanostructure in the conducting polymers. In fact, as with inorganic amorphous semiconductors, conduction in such relatively disordered materials is mostly a function of "mobility gaps" with phonon-assisted hopping, polaron-assisted tunnelling, etc., between localized states.

Conclusion: From the results it is evident that the level of increase in the electrical and thermal conductivities is within the range of the already known conductive polymers. The thermal conductivities were in the ranges within $10^{-2} \mathrm{cal} / \mathrm{cm} / \mathrm{s}$ making them good and cheaper alternatives to be used in systems where such polymers are applied e.g in coating and potting of electronic components and the like. Suitability of conductive polymers in this application is thermal conductivity in the range of $10^{-3}-10^{-1} \mathrm{cal} / \mathrm{cm} / \mathrm{s}$

The Electrical conductivities were in the range of $10^{-6}$ $\mathrm{S} / \mathrm{cm}$ which falls into the range of the electrical conductivity of other conductive polymers which have found use in various applications like electromagnetic interference shielding, transparent packaging of electromagnetic components, solar batteries, nonlinear optical display devices, smart fabrics and 
recordings ,Production of capacitors etc In conclusion recycling of polymeric materials is a sine qua non to effective waste management extrapolating to a cleaner and healthier environment. This new dimension of its application in the evolving world of conductive polymers becomes well developed it will lead to the production of various range of cheap semiconductors. This will drastically reduce cost of production and improve the GDP of various industrialized societies and every other nation.

\section{REFERENCES}

Aderogba K.A (2014)', Polymer wastes and management in cities and towns of Nigeria and sustainable environment "'in Peak Journal of Physical and Environmental Science Research Vol.2 (1), pp. 1-12

Beth S (2012). Simple ways to reuse and recycle your holiday décor. London: World Street Journal (Saturday, 28 ${ }^{\text {th }}$ December).

Biodun N.(1997), conducting polymers, Blackwell publishers London $3^{\text {rd }}$ Ed. ISBN978 - 3674, pp 14.

Brandup, J. and Immergnt, E.H. 1989. PolymerHandbook. Wiley- Interscience: New York, NY. 80.

Brown L.T, Lemay E. H Jr., Brusten.E.B,(2009) Chemistry, The central science, modern materials 11ed.( Prentice-Hall Inc.)

Dahman., S. J(1999) synthesis, characterization and application of inherently conducting polymers, Journal of polymer engineering and science, vol. 39,11 .

Evans D, Bishop I (2000). Resource conservation and recycling. Oxford: Oxford University Press; pp. $32,289-313$

Inzelt G.(2008) Conducting polymers, A New Era in Electrochemistry Monographs, Electrochemistry Springer ,2008, pp $265-267$.

Magic, K.D. and Pelitsky, V.E. 1984. Compendium of thermophysical Properties; Measurement Methods, Vol.1. Plerium Press: New York, NY. 443.

Monika R.K(2010) Synthesis of conducting polymers and their characterization, Indian Journal of Pure and Applied Physics. vol.48,July 2010, 524

Naarman H.(2000), Polymers Electrically conducting, (Ullman's Encyclopedia of Industrial Chemistry,)
Nalwa H.S (2000) Handbook of Nano structured and materials Nano Technology, Academic press .New york, NY USA.Volume 5, 501 -575

Ogwueleke T (2006). Municipal solid waste characteristics and management in Nigeria. Iran J. Environ. Health Sci. Eng. 6(3)173-180

Parker, P.S. (1994). Concise Encyclopaedia of Science and Engineering, 3rd Ed. McGraw- Hill: New York, NY. 456-457.

Rochman CM (2013). Plastics and priority pollutants: A Multiple Stressor in Aquatic Habitats. Environ. Sci. Technol. 47(6):2439-2440.

Saricifici, N.S(1997) Handbook of Organic Conductive Molecules and Polymers, World Scientific, Singapore, vol.1-4 wiley \&sons Ltd Chichester Edited by H.S Nalwa

Seymour R.B, Chery.T. (1986)History of poly olefins D. Reidd Dordrecht, The Netherlands.

Wanekaya A.K, Lei Y., Bekyarova E., Chen W., Haddon .R,(2006) Fabrication and properties of conducting polypyrrole, Electro analysis 18, No 11. ( wiley publishers wiley-VCH weinhem U.S.A., 2006) 1047-1054

Weber R, Gaius C, Tysklind M, Johnston P, Forter M, Hollerti H, Heinisch E, Holoubeck I, Lloyd-Smith M, Masunaga S, Moccarelli P, Santillo D, Seike N, Symons R, Torres JP, Verta M, Varbelow G, Vijqen J, Watson A, Costner P, Woelz J, Zenneqq M (2008). Dioxn- and POP- contaminated Sites Contemporary and Future Relevance and Challenges: Overview and Background, Aims and Scope of the Series. Environ. Sci. Pollut. Res. Int. 15(5):363-93.

Zaini S (2011). Municipal solid waste management in Malaysia. J. Appl. Sci. Environ. Sanit. 6(1):29-38. 